\title{
ACULTURACIÓN EN ESCOLARES MAPUCHES DE LA PROVINCIA DE CAUTÍN. IX REGIÓN.*
}

\author{
Amelia Gaete T.**
}

\begin{abstract}
ANTECEDENTES GENERALES
La aculturación es un fenómeno al que están expuestos con mayor o menor fuerza los escolares mapuches de La Araucanía debido al impacto que genera en ellos la educación sistemática, en otros términos esto se debe a que la Escuela Básica se ciñe a los curriculos nacionales dejando de lado las diferencias etnoculturales de los educandos.

El trabajo de investigación que se presenta en esta ocasión consiste en el Análisis de Contenido de una Escala de Aculturación para Niños Mapuches (EANM), elaborada en el marco de un Proyecto de Investigación de la Universidad de la Frontera (M. Denegri, A.Gaete, M. E. Gonzalez y otros, 1990); y cuyos resultados serán importantes para otro proyecto en ejecución, sobre familias rurales mapuches y no mapuches. (A. Gaete y A. Petit). ${ }^{1}$
\end{abstract}

\section{MARCO TEÓRICO}

Los autores Redfield, Linton y Herskovits, plantean: «La aculturación es el conjunto de los fenómenos resultantes de que grupos de individuos pertenecientes a culturas distintas entren en contacto continuo y directo, y de los cambios que se producen en los modelos (patterns) culturales originarios de uno o de ambos grupos» (Bastide, 1977:40).

Por lo tanto, en nuestros sujetos de estudio sabcmos que son los escolares mapuches y chilenos. además de sus familias y maestros (los individuos) poseedores de sus respectivas culturas, los que entran en contacto.

Es posible hablar de 3 tipos de aculturación: forzada, libre y planificada.

La primera se visualiza en los casos de conquista y colonización, cuya orientación va en exclusivo provecho del grupo dominante, generalmente provoca résistencia al cambio cultural por parte del grupo conquistado o colonizado.

La segunda se presentan espontáneamente cuando dos o más grupos entran en contacto.

Y la planificada, se encuentra en distintos tipos de sociedades generalmente concretizada en los sistemas educativos. especialmente cuando las minorias étnicas deben incorporar a sus hijos a la educación sistemática, la cual se orienta a los patrones culturales de la sociedad dominante, es lo que ocurre en la práctica en la Región de La Araucanía, con la etnia Mapuche.

\footnotetext{
* Ponencia presentada en el IV Congreso Chileno de Sociología. realizado en Santiago de Chile. entre el 27 y 29 de Agosto de 1992, en el Centro de Extensión Universidad Católica

** Universidad de La Frontera, Temuco.
} 
Para explicitar más el fenómeno de aculturación, es necesario definir el concepto de cultura a trabajar. Esta se entiende desde la perpectiva sociológica como «todas las costumbres, creencias, valores, conocimientos y artefactos que se aprenden y los símbolos que se comunican constantemente entre un conjunto de personas que comparten una forma de vida común» (Light, Keller y Calhoun, 1991: 79). La cultura incluye aspectos objetivos como artefactos materiales, y también aspectos subjetivos como normas, valores y creencias, esto conlleva a patrones de comportamiento específicos para cada grupo humano, los que están determinados culturalmente según correlatos cognoscitivos. Es por ello, que la cultura se expresa de diversas formas, con indicadores culturales objetivos y subjetivos.

En nuestra investigación, se trabajó con 5 indicadores considerados de gran significación para la cultura mapuche, como son: a) Familia . b) Vivienda , c) Lenguaje, d) Socialización, y e) Religión.

La familia entendida como indicador objetivo. Según Goode es la única institución social fuera de la religión, que se desarrolló formalmente en todas las sociedades (1966: 8); siendo la base fundamental e instrumental de una más amplia estructura social, pues todas las demás instituciones dependen de sus contribuciones. La conducta funcional que se aprende dentro de ella, pasa a ser modelo conductual requerido cn otros segmentos de la sociedad. A través de la familia se transmite y se mantiene viva la cultura.

En todas las sociedades, la familia cumple con las funciones siguientes: a) Reproductora biológica, b) Manutención de sus miembros, c) Colocación social de los hijos, d) Socialización de sus miembros en una atmósfera de intimidad, y e) Control social de sus integrantes basado en los patrones culturales socialmente establecidos.

La vivienda es considerada también como indicador objetivo del sistema cultural. Siendo la organización del espacio o del habitat del grupo, que tiende mediante su diseño a la satisfacción de las necesidades biológicas, sociales, psicológicas y culturales de las personas que la comparten.

Como indicador subjetivo a través del cual se transmite la cultura. se entiende el lenguaje. La lengua es un sistema verbal y/o escrito de símbolos con reglas sobre la forma como pueden enlazarse aquellos símbolos que transmiten significados complejos. Mediante ella, sc conservan experiencias y significados que van a constituir una herencia para las nuevas generaciones. Permite además, trascender el presente preservando el pasado e imaginar el futuro. Según Sapir. el mundo real se conforma según los hábitos lingüísticos de un grupo determinado; por lo tanto. la forma de ver, escuchar y obtener experiencias depende de dichos hábitos y predispone a la comunidad a hacer sus propias interpretaciones.

Algunos estudios sobre lenguas amerindias postulan que los procesos cognitivos, especialmente el pensamierito, dependen de categorías linguísticas; cuando el niño aprende una lengua comienza a categorizar el mundo. La diversidad de lenguas presenta diferencias en la estructura del pensamiento (Peronard, 1978). De ahí, la importancia del rol que desempeña la lengua en el conocer y el pensar el mundo que lo rodea.

Otro indicador subjetivo importante dentro de la cultura, ha sido la Socialización Básica. según Inkeles (Goslin. 1969), entendida como un proceso mediante el cual el niño inserto en una cultura adquiere atributos tales como, experiencias, conocimientos, valores. actitudes. necesidades y motivaciones, patrones cognitivos. afectivos y connotativos, los que se enmarcan en ciertos aspectos fundamentales de la cultura de pertenencia tales como son su: folklore. 
mitología, diversiones, historia. adiestramiento en el quehacer manual, formas de conducirse en su grupo social. e instrucciones prácticas de sus usos y costumbres, todo lo cual permitirán al niño adaptarse a su ambiente físico y sociocultural. La socialización se da fundamentalmente en el contexto familiar, luego el proceso continúa en la escuela y los diferentes medios en que se mueve el individuo.

Por último, consideramos la religión, también como indicador subjetivo de la cultura, siendo un sistema más o menos coherente de creencias y prácticas relativas al orden sobrenatural de fuerzas o seres de diverso tipo. Determina una visión y estructura de mundo, al proporcionar explicaciones de aquellos aspectos de la vida que no es capaz de entender el hombre mediante su lógica, ciencia y tecnología, se apoya preferentemente en criterios de fe para creer en algo.

Desde la perspectiva funcionalista:

«la religión hace que el individuo se identifique con su grupo,le dá apoyo en la incertidumbre, lo consuela en el desengaño, lo vincula con los objetivos de la sociedad, fortalece su moral y le proporciona elementos de identidad. Actúa para reforzar la estabilidad y la unidad de la sociedad, apoyando el control social, acrecentando los valores y metas establecidos, y proporcionando los medios para superar la culpa y la alienación.» (O’Dea, 1978:27).

Las creencias religiosas se institucionalizan socialmente, apoyadas en códigos y principios valóricos, que conllevan una sanción a los que no los acatan. esto implica todo un ordenamiento y estructura organizacional del quehacer religioso en una sociedad determinada. Las diversas religiones se diferencian en cuanto a su doctrina, prácticas y organización.

En el estudio empírico llevado a cabo en las escuelas ya señaladas se tomó como base la Teoría Sistémica, partiendo por una concepción sistémica de la cultura, y enfrentando desde esa perspectiva el fenómeno de la aculturación.

\section{METODOLOGíA}

Se trabajó una muestra de 230 escolares mapuches de ambos sexos, cuyas edades fluctuaron entre los 6 años y 5 meses hasta 12 años y 5 meses, matriculados en 11 escuelas municipalizadas de las comunas de Pucón, Pto. Saavedra, Temuco, Vilcún y Villarrica, todas pertenecientes a la Provincia de Cautín, Novena Región.

El instrumento que se aplicó a la muestra estudiada fue una Escala de Aculturación para Niños Mapuches (EANM). La que está conformada por 5 subescalas basadas en 5 variables consideradas esenciales para determinar rasgos fundamentales de una cultura como son: Familia, Vivienda, Lenguaje, Socialización y Religión. Se trabaja como un cuestionario con respuestas dicotómicas por cada item, con puntuaciones cuyos valores apuntan a la posesión de aspectos o elementos propios de la cultura mapuche o ausencia de éstos, lo que indicaría menor o mayor grado de acercamiento con la cultura chilena respectivamente. Los puntajes de la Escala de Aculturacion oscilan entre 0 y 33 puntos. se distribuyen según los ítemes que conforman cada subescala, debido a que las respuestas son dicotómicas, se otorga 1 punto al presentar características propias de la cultura mapuche y 0 punto en caso contrario. Por lo tanto. a mayor puntaje obtenido, menor grado de aculturación, y viceversa. 
Se aplicó mediante la modalidad de entrevista individual con preguntas breves formuladas en castellano. Para las subescalas Familia y Vivienda, se utilizó 3 sets de láminas pares, consideradas como instrumentos de autoidentificación étnica. Un set contiene imágenes de familia chilena versus mapuche, otro presenta actividades al interior de una vivienda para ambos grupos, y un tercer set imágenes de actividades fuera de la vivienda tanto para mapuches como chilenos. Las láminas eran presentadas al escolar, quién debía señalar con cual de estos grupos se sentía más identificado. Según las respuestas se aplicaba el puntaje. 0 si manifestaba pertenecer al grupo chileno, y 1 punto cuando su autoidentificación correspondía a la etnia mapuche.

Las subescalas restantes: Lenguaje. Socialización Básica y Religión se trabajaron con ítemes de preguntas con respuestas dicotómicas y sin imágenes.

Se calculó la confiabilidad de la Escala y las subescalas mediante la técnica de la multipartición aplicando el Coeficiente Kuder Richarson, cuyos resultados indicaron consistencia interna entre ítemes.

La validez del instrumento se obtuvo mediante la verificación de dos hipótesis.

La primera hipótesis (HI), elaborada para corroborar la validez del constructo, denominada de diferencia de grupos, estaba orientada a determinar la existencia de dos grupos de educandos mapuches: aquellos que tienen mayor contacto con escolares chilenos y cuyo hábitat ecológico ya ha sido modificado, y otro de menor contacto con educandos chilenos y pertenecientes a ambientes ecológicos escasamente modilicados. Los resultados indicaron que los escolares mapuches al tener mayor contacto con niños pertenecientes a la cultura chilena y encontrarse viviendo en lugares más modificados, presentan mayor grado de aculturación que el otro grupo de escolares mapuches, quienes demostraron tener un menor grado de aculturación.

La segunda hipótesis $(H 2)$, denominada de validez de constructo convergente, permitía correlacionar dos instrumentos que miden el mismo constructo. En este caso, se trabajó el instrumento Percepción del grado de Aculturación de Alumnos Mapuches (PGAAM), elaborado en forma teórica por Cornejo et als. en $1988^{2}$ En nuestro estudio fue aplicado a los profesores de los alumnos sometidos a la Escala de aculturación.

Los resultados obtenidos mediante la prueba $\mathrm{r}$ de Pearson, indicaron correlación negativa entre los puntajes del PGAAM y los de la EANM (-.67). La hipotésis planteaba «Los sujetos que obtengan un alto puntaje en la EANM tenderán a ser clasificados por sus profesores como teniendo un bajo grado de aculturación”.

\section{PROCEDIMIENTO}

La Escala de Aculturación (EANM), fue aplicada al total de la muestra en el invierno y primavera de 1990, en los 11 establecimientos educacionales elegidos de la provincia de Cautín. La administración se realizó en forma individual a cada escolar, mediante la modalidad de entrevista, llevada a cabo por el equipo de investigación conformado por psicólogos, una socióloga y los alumnos tesistas de la carrera de Psicología. (Rascheya y Ripoll) ${ }^{3}$, quienes estaban encargados de determinar los aspectos metodológicos de la EANM. en cuanto a su validez y confiabilidad.

Una vez que la Escala de Aculturación fue aplicada. y sus resultados indicaron que era confiable como instrumento y válida para la muestra de escolares mapuches, se procedió a efectuar el Análisis de Contenido, a fin de poder plantear «Hipótesis Ex post Facto». 
Con el objeto de determinar grados alto, medio y bajo de aculturación en los escolares estudiados, se tricotomizó la variable respectiva, para lo cual se empleó los puntajes brutos obtenidos en la escala del total muestral, se trabajó frecuencias absolutas, y acumuladas para determinar treciles, los que permitieron hacer los cortes respectivos que la tricotomizan.

Por otra parte, cada subescala fue analizada en sus diversos ítemes para visualizar su distribución cuantitativa y cualitativa.

\section{RESULTADOS}

Los puntajes de la EANM se distribuyeron entre 0 y 31 , siendo el máximo teórico a obtener 33 puntos, los que se agruparon de la siguiente forma:

De 0 a 7 puntos $=$ Grado de Aculturación Alta

De 8 a 16 puntos $=$ Grado de Aculturación Media

De 17 a 31 puntos = Grado de Aculturación Baja

La distribución de la Escala en la muestra estudiada, según grados de aculturación y sexo, se presenta en el cuadro siguiente

\section{CUadro $\mathrm{N}^{\circ} 1$}

Grados de aculturación SEGÚN SEXo

Cifras absolutas y Relativas

\begin{tabular}{lcccccccc}
\hline & Alta & $\%$ & Media & $\%$ & Baja & $\%$ & Total & $\%$ \\
\hline Hombres & 33 & 39.3 & 39 & 50.0 & 37 & 54.4 & 109 & 47.4 \\
Mujeres & 51 & 60.7 & 39 & 50.0 & 31 & 45.6 & 121 & 52.6 \\
Total & 84 & 100.0 & 78 & 100.0 & 68 & 100.0 & 230 & 100.0 \\
& & 36.5 & & 33.9 & & 29.6 & & 100.0 \\
\hline
\end{tabular}

Al observar el cuadro № 1 , vemos que la variable aculturación presentó mayor tendencia al grado Alto $(36.5 \%)$. lo cual nos permite aseverar que el efecto de la educación sistemática en la escuela ha incidido en los escolares mapuches.

En cuanto al sexo, las mujeres presentan porcentajes mayores de AltaAculturación (60.7\%) que los hombres $(39.3 \%)$. la Media fue igual para ambos sexos, y la Baja indica mayor porcentaje en los escolares hombres $(54.4 \%)$.

A objeto de analizar que incidencia tiene la edad en la muestra estudiada, se incorporó esta variable en el cuadro siguiente: 
Cuadro No 2

Grado de aculturación SEGÚN SEXo Y EDAD

(CIFRAS ABSOLUTAS)

\begin{tabular}{lccccccc}
\hline Años & \multicolumn{3}{c}{ Hombres } & \multicolumn{3}{c}{ Mujeres } \\
& Alta & Media & Baja & Alta & Media & Baja & Total \\
\hline $6.5-9.5$ & 18 & 19 & 15 & 34 & 22 & 15 & 123 \\
$9.6-12.5$ & 15 & 20 & 22 & 17 & 17 & 16 & 107 \\
Total & 33 & 39 & 37 & 51 & 39 & 31 & 230 \\
\hline
\end{tabular}

Se agrupó la variable edad, en los tramos de 6.5 a 9.5 años categorizando al grupo como el de menor edad, y el otro que va de 9.6 a 12.5 años el de mayor edad.

Según los datos obtenidos, podemos decir que a menor edad de las escolares mujeres mayor grado de aculturación $(N=34)$, en cambio a mayor edad de los escolares hombres menor grado de aculturación $(n=22)$. Los resultados indican que la edad podría considerarse como variable interviniente en este caso, ya que el sexo según el Cuadro № 1 indicaba diferencias, y faltaba determinar que otro factor estaba incidiendo en ello.

Otra variable importante en el estudio, es el lugar geográfico en que viven los escolares, cuyos datos se presentan en el cuadro que sigue.

\section{CUadro № 3}

Grados de aCUlturación SEgún COMUNas y localidades

(CIFRAS ABSOLUTAS)

\begin{tabular}{|c|c|c|c|c|}
\hline $\begin{array}{l}\text { Comunas y } \\
\text { Localidades }\end{array}$ & Alta & Media & Baja & Total \\
\hline \multicolumn{5}{|l|}{ Temuco: } \\
\hline Licanco & 1 & 11 * & $11 *$ & 23 \\
\hline $\begin{array}{l}\text { Pto. Saavedra: } \\
\text { Isla Huapi }\end{array}$ & $\cdot$ & 4 & $18 *$ & 22 \\
\hline \multicolumn{5}{|l|}{ Vilcún: } \\
\hline Gral. López y Cajón & 9 & $11 *$ & 9 & 29 \\
\hline Vega Redonda & 5 & $32 *$ & 21 & 58 \\
\hline $\begin{array}{l}\text { Villarica: } \\
\text { Villarrica. Nancul } \\
\text { y Lican Ray }\end{array}$ & $48 *$ & 12 & - & 60 \\
\hline $\begin{array}{l}\text { Pucón: } \\
\quad \text { Pucón, Caburgua y }\end{array}$ & \multicolumn{3}{|c|}{ Pucón: } & \\
\hline Palguín Bajo & $21 *$ & 8 & 9 & 38 \\
\hline Total 84 & 78 & 68 & 230 & \\
\hline
\end{tabular}


Al analizar los datos del Cuadro № 3, vemos que en la localidad de Licanco, los escolares presentan igual distribución en los grados de aculturación Media $(\mathrm{N}=11)$, en cambio Isla Huapi tiene cifras significativas de Baja aculturación. muy pocos casos en el grado de aculturación Media, y ninguno presenta Alta aculturación.

En ambas localidades, se observa en la realidad, mayor tendencia a mantener los patrones culturales ancestrales de la etnia mapuche, aún cuando Licanco queda a pocos kilómetros de Temuco, no así la Isla Huapi que se encuentra alejada de centros poblados mayores, pudiendo defenderse del impacto cultural foráneo.

En cuanto a las localidades de Cajón, Gral. López y Vega Redonda sus indicadores apuntan a grados de aculturación Media, las dos primeras son zonas semirurales, y sus escuelas están en el pueblo respectivo, pero los escolares vienen de zonas rurales, la influencia del medio geográfico puede ser la explicación de esos resultados, en cambio en Vega Redonda, la población escolar mayoritariamente es mapuche, y con amplio contacto interétnico en la localidad.

En las comunas de Villarrica y Pucón, las cifras nos entregan información relativa a grados de aculturación Alta, no presentándose datos de escolares con Baja aculturación en Villarrica. lo cual se debe al alto grado de contacto interétnico que hay en ambas comunas, sobretodo en épocas de vacaciones por la afluencia de turistas, además que los niños que iban a las escuelas de Villarrica, Lican Ray y Pucón provenían generalmente de lugares rurales ubicados cerca de la ciudad. A la vez, los de Palguín Bajo, Caburgua, y Ñancul asistían a las escuelitas del lugar. pero igual están expuestos a los efectos de cambios socioculturales y del entorno físico, al estar ubicados en zonas eminentemente turísticas.

Con el objeto de determinar la existencia de asociación entre las variables: Grados de Aculturación y Localidad Geográfica, se calculó la prueba de Chi Cuadrado. la cual fue significativa con una probabilidad de $95 \%$, luego se trabajó con el coeficiente V de Cramer lò que nos dió 0.22 , siendo baja la correlación entre las variables, pero nos señala asociación entre el lugar geográfico y el grado de aculturación de los escolares estudiados, lo que se debe al mayor o menor contacto interétnico que cllos tienen, y a la vez esto incide en los cambios que se generen en el entorno físico, por ejemplo las localidades de las comunas de Villarrica y Pucón han sido ampliamente modificadas por efecto del turismo.

Ahora el siguiente análisis, corresponde hacerlo en cada una de las subescalas e ítemes que conforman la EANM.

\section{SUBESCALA FAMILIA}

Tres sets de láminas forman parte de la prueba de autoidentificación étnica, y está constituida por:

Un set,que contiene imágenes de padre y madre mapuche y dos hijos un varón y una niña. todos con atuendos típicos mapuches, versus igual composición familiar con atuendos campesinos chilenos. Un segundo set referido a labores de la familia con igual número de integrantes al interior de la vivienda cuyas diferencias están en el tipo de vivienda. ruka mapuche y casa campesina para los chilenos. El tercer set orientado a trabajos fuera de la vivienda y alrededor de ella, con igual número de integrantes que se diferencian en tipos de vivienda, sea ruka mapuche o vivienda campesina chilena. (Mostrar láminas). 
Del total de 230 escolares que forman parte de la muestra, al presentárseles los 3 sets de láminas de la subescala. 38 de ellos sé autoidentificó como integrante de la familia mapuche. representando sólo el $16.5 \%$ del total, dentro de ese porcentaje se ubican preferentemente los escolares de Isla Huapi, Licanco, Palguín Bajo y Vega Redonda.

\section{SUBESCALA VIVIENDA}

De los diversos ítemes que la conforman, los más significativos fueron, mantener Ruka-Cocina con techo de paja, y contar con Fogón para cocinar. 27 escolares señalaron contar con RukaCocina lo que equivale al $11.7 \%$ solamente del total, y corresponden a los residentes de Licanco, Isla Huapi, y Vega Redonda. La ruka-cocina es aquel espacio destinado a la preparación de los alimentos, comer, calefaccionarse, guardar las cosechas, e interactuar familiarmente; por lo tanto, se tiene otra vivienda para dormir.

Nos interesaba saber donde cocinaba la mamá, y 100 niños dijeron que en el FOGON, ubicándose el $43.5 \%$ de los hogares, distribuidos en las diferentes localidades.

\section{SUBESCALA LENGUUAJE}

Aquí se contemplaron diferentes ítemes para saber quienes manejaban el MAPUDUNGUN o lengua mapuche.

101 niños demostraron manejar su lengua materna. de ellos 52 niñas y 49 varones, es decir, el $44 \%$ aproximadamente del total estudiado. En cambio, cl manejo del mapugundun con el maestro, es muy limitado y alcanza sólo a 38 niños, es decir al $16.5 \%$ de la muestra. Probablemente se deba, a que los contenidos programáticos se desarrollan en lengua española, y no hay oportunidades de hablar en mapuche en las clases, sólo en los recreos o espacios extraprogramáticos.

En cuanto a los progenitores. 63 padres hablan mapuche $(27.4 \%)$ y 58 madres $(25.2 \%)$. Sin embargo en la categoría otros parientes, que comparten el habitat familiar, como ser hermanos, tíos y abuelos, en 138 hogares, ellos manejan su lengua de pertenencia representando el $60.0 \%$ de la muestra. Y por último en la categoría habla toda la familia, la cifra alcanza a 78 grupos familiares $(40.0 \%)$, que comparten la vida común en su lengua de origen.

\section{SOCIALIZACIÓN BÁSICA}

Los ítemes contemplados se orientaron a indagar los siguientes aspectos: a) Contacto del escolar con niños no mapuches o huincas, b) Sólo con mapuches; c) Practicar juegos, y d) Manejar instrumentos mapuches en el grupo familiar; ye) Tener conocimientos de relatos orales mapuches.

133 niños tienen amigos no mapuches o huincas $(57.8 \%)$, siendo más significativo en las localidades de Lican Ray, Pucón y Villarrica. En cambio 121 escolares señalaron sólo tener amigos mapuches $(52.6 \%)$ lo que se observó con mayor fuerza en Licanco, Isla Huapi, Palguín Bajo y Vega Redonda.

El practicar juegos propios de la cultura mapuche, como Chueca o Palín y otros, se observó en 88 familias que aún los mantienen vigentes $(38.3 \%$ ). La costumbre de tocar instrumentos 
típicos, tales como Pifilka, Trutruka. Trompe, Kultrún entre otros, se conserva en 98 grupos familiares $(42.6 \%)$.

Y en relación al conocimiento del escolar sobre relatos mapuches, 102 dicen saber de ellos (44.3\% ), lo que demuestra el traspaso de la cultura oral, a los niños por parte de los adultos. Los personajes más conocidos en órden decreciente son: ANCHIMALLEN, CHONCHON, CHERRUFE, SHUMPALL, MANQUIAN, PILLAN, HUEKUFE, CUENTOS DE ANIMALES, WITRANALHUE, TREN TREN, PIWUCHEN, y CUERO DEL DIABLO.

$\mathrm{Al}$ analizar los lugares geográficos de procedencia de los escolares, existe una relación directa entre relatos con personajes que viven en el agua (SHUMPALL y MANQUIAN) y habitar en Isla Huapi y Lican Ray.

Los lugares, donde con más fuerza se mantiene la tradición oral de los distintos relatos señalados, son Isla Huapi, Licanco, y Vega Redonda, en las otras localidades sólo se detectaron algunos.

\section{SUBESCALA RELIGIÓN}

La conformaron ítemes destinados a indagar: a) Participación familiar en ceremonias propias de la cultura, como NGUILLATUN y MACHITUN, b) Acudir en caso de enfermedades donde la MACHI, c) Creer en los espíritus cuidadores o NGEN, y en seres míticos.

En 139 hogares, han participado en las ceremonias del Nguillatun y Machitun (60.4\%), por lo tanto, más de la mitad de las familias de los escolares, siguen manteniendo las prácticas ancestrales de rogativas a seres sobrenaturales.

Un grupo significativo de 95 familias, recurre a sanarse donde Machi, representando el $41.3 \%$, lo que indica la persistencia de la medicina tradicional indígena, en las localidades estudiadas.

Otros aspectos importantes a indagar, han sido las creencias en espíritus cuidadores o Gnen, 31 escolares aceptan que existen, la cifra del $13.5 \%$ nos indica, que este aspecto de la cultura se está perdiendo. Probablemente la adquisición, a través de la escuela, de conocimientos científicos en torno a los fenómenos naturales, sea la explicación a éste hecho.

Se mantiene con más vigor, la creencia en seres míticos, como los de relatos ya señalados (SHUMPALL, PILLAN, HUEKUFE y otros), encontrándose en esta situación 57 escolares, que corresponden al $24.8 \%$, cifra más alta que la anterior.

A modo de conclusión, podemos decir que la investigación sobre el fenómeno de la Aculturación en escolares rurales mapuches, nos permite plantear algunas hipótesis ex post facto:

- A mayor edad de los escolares varones, menor grado de aculturación.

- A menor edad de las escolares mujeres, mayor grado de aculturación.

- Existe relación entre lugar geografico y grado de aculturación.

Las dos primeras hipótesis, se podrían explicar en el sentido de que las niñas son más receptivas. a temprana edad, a los contenidos programáticos de la escuela. En cambio el niño varón. al tener más edad. manifiesta su identidad étnica a través de la cultura de pertenencia. seguramente reforzada por el grupo familiar. 
La tercer a hipótesis, resulta fácil de explicar, debido a que en los lugares geográficos. con menor contacto interétnico los escolares manifiestan tener menor grado de aculturación. Es el caso de Isla Huapi y Licanco. En cambio, en todas las localidades turísticas de la muestra, Villarrica, Pucón. Lican Ray, Palguín Bajo, los niños presentaban mayor grado de aculturación. Y en aquellas escuelas ubicadas en zonas semirurales, tales como Cajón, Gral. López, los escolares aún cuando provenían de lugares rurales, tenían grados medios de aculturación. Esto también ocurría en Vega Redonda, aún siendo área rural, debido al contacto interétnico.

De la tercera hipótesis se puede desprender la siguiente:

- A mayor contacto interétnico del escolar mapuche, éste presentará mayor grado de aculturación, y viceversa.

A partir del análisis de contenido de las subescalas, ha sido posible adentrarse en la compleja estructura de la cultura mapuche, la que mantiene su vigencia a través de variadas manifestaciones socioculturales. Mediante el lenguaje o mapudungun, traspasa conocimientos pragmáticos de la vida cotidiana. educa a los niños y jóvenes. socializa, y también entrega contenidos rituales y religiosos, a veces expresados en el discurso social, de los relatos orales en general, o míticos en particular.

Los sistemas de creencias religiosas, están presentes en las ceremonias de rogativas, tales como Nguillatun y Machitun, en que participa toda la familia.

Los personajes míticos y de la naturaleza, aún son traspasados a las nuevas generaciones, por medio de relatos y cuentos de animales, los que tienen siempre una intencionalidad:

«El relato cumplirá así, una función de entretener, educar, conmover, recordar, animar y hasta en ocasiones, de acompañar en el trabajo. En todo caso, es coincidente en la inclusión de emociones, manera de concebir el mundo y transmisión de la cultura." (Contreras.1990:50).

Persiste en algunos escolares, la creencia en los espíritus cuidadores de la naturaleza o Gnen, lo que tiene enorme importancia del punto de vista ecológico, al permitir mantener el respeto y cuidado de la naturaleza. considerada sagrada para el pueblo mapuche.

En relación con éste tema, M. Ester Grebe ha elaborado un paralelismo entre los sistemas de creencias Aymara y Mapuche, con respecto a dos calegorías de espíritus cuidadores de la naturaleza: los del agua y de la montaña, (1988). En este sentido a modo de conclusión, la autora señala. que ambas categorías de espíritus forman parte de un subsistema de creencias relacionadas con el mundo terrestre. Que la naturaleza virgen, no tocada por el hombre, influye en la interacción de éste con su entorno natural, etc... (pp.75-76).

Finalmente, creemos que la educación sistemática impartida en zonas rurales con alta matrícula de escolares mapuches, debe ser pertinente al grupo, de modo que permita la mantención de los elementos esenciales de su cultura. con el objeto de evitar los conflictos culturales, a los cuales está expuesto el niño o el joven mapuche, tanto en la escuela como en su contacto con la sociedad mayor.

La lengua que es el vehículo de transmisión por excelencia, no se contempla en los programas de estudios, salvo contadas excepciones de educación bilingue. En este sentido. G. Sepúlveda ha señalado, que la enseñanza idiomática es uno de los factores de que persista un divorcio, entre lo que se enseña y lo que se aprende. Ya que cada lengua o repertorio lingüístico va aparejado con un conocimiento. percepción, y compontamiento cultural. Y esto debe eslar presente en la tarea pedagógica (1988). 
Junto a la lengua, la escuela debe contemplar en el proceso de enseñanza-aprendizaje, el manejo de realidades propias del grupo étnico. mediante el traspaso de su tradición oral. expresada en cuentos de animales, míticos, y otros de entretención; en vez de proyectar en sus mentes relatos o cuentos foráneos de personajes o entes inexistentes en su cultura de pertenencia.

\section{NOTAS}

1. Proyectos de Investigación, financiados por la Dirección de Investigación y Desarrollo de la Universidad de la Frontera: «Estudio comparativo de los niveles de Desarrollo Cognitivo y Niveles de Pensamiento según Piaget, en escolares mapuches y no mapuches rurales». M. Denegri, A. Gaete, M. E. González y otros. 1990-1991. «Tradicionalismo-Modernismo en familias rurales mapuches y no mapuches». A. Gaete, A. Petit y otros. 1991-1992.

2. Construcción de una Escala de Aculturación para Adolescentes Mapuches. Tesis para optar al Grado de Licenciado en Psicología. de la Universidad de la Frontera. Cornejo et als.1988. Temuco.

3. Construcción de una Escala de Aculuración para Niños Mapuches. Tesis para optar al Grado de licenciado en Psicología. Universidad de La Frontera. Rascheya y Ripoll 1991. Temuco.

\section{BIBLIOGRAFIA}

Bastide, R. (1977), Antropología Aplicada.Ed. Amorrortu. Buenos Aires.

Contreras, V.(1990), «Los relatos orales mapuches: Proyecto literario y educativo». En Actas de Lengua y Literatura Mapuche 4, 45-52. Universidad de la Frontera. Tenuco.

GaETE, A. (1989), «El Epeu Mítico de Shumpall desde una perspectiva sociológica», en Actas de Lengua y Literatura Mapuche 3, 159-175. Universidad de La Frontera. Temuco.

Goode, W. (1966), La Familia. Edit. UTEHA. México.

Grebe, M. E. (1988), «Algunos paralelismos entre los sistemas de creencias Mapuche: los espíritus del agua y de la montaña». En Boletín Muséo Regional de la Araucanía (Temuco) 3: 71.78

Light, D., Kel.ler, S., y Calhoun C. (1991), Sociología. Quinta Edición. Mc Graw Hill. Colombia.

O'Dfa, T. (1978), Sociología de la Religión. Ed. Trillas, México.

Peronard, M. (1978), Mente, Lenguaje y Cultura. Ed. Universitaria Santiago.

Sepúlveda, G. (1988), «Educación y Futuro en la IX Región», en Estudios Sociales № 55. CPU. Santiago

Stuchuk, M. (1974), Rasgos de la Sociedad Mapuche Contemporánea. Universidad Católica de Chile. Ed. Nueva Universidad. Santiago. 